\title{
The prevalence, distribution and impact of peripheral neuropathy among Danish patients with cancer - A population-based cross-sectional study.
}

\section{Sebastian Werngreen Nielsen ( $\sim$ sewn@regionsjaelland.dk)}

Zealand University Hospital: Sjaellands Universitetshospital Roskilde https://orcid.org/0000-00033584-9154

\section{Christina H. Ruhlmann}

Odense University Hospital: Odense Universitetshospital

\section{Lise Eckhoff}

Odense University Hospital: Odense Universitetshospital

\section{Jørn Herrstedt}

Zealand University Hospital: Sjaellands Universitetshospital Roskilde

\section{Susanne 0. Dalton}

Zealand University Hospital: Sjaellands Universitetshospital Roskilde

\section{Research Article}

Keywords: Neurological complications, peripheral neuropathy, cancer treatment, adverse effects, chemotherapy-induced peripheral neuropathy

Posted Date: April 23rd, 2021

DOI: https://doi.org/10.21203/rs.3.rs-375423/v1

License: (9) This work is licensed under a Creative Commons Attribution 4.0 International License. Read Full License

Version of Record: A version of this preprint was published at Acta Oncologica on November 30th, 2021. See the published version at https://doi.org/10.1080/0284186X.2021.2007283. 


\section{Abstract}

Purpose: Prevalence of peripheral neuropathy (PN) has been studied in patients undergoing treatment with taxanes, platinums and vinca alkaloids. The prevalence is unknown in the general oncological cancer population, characterized by advanced age, comorbidities and heterogeneous treatments.

Methods: A cross-sectional survey was administered to all adult patients, attending outpatient services at three Danish departments of oncology. The survey contained the EORTC-QLQ-C30, the EORTC-CIPN20, the GAD7 and PHQ9 questionnaires. A high PN symptom score was defined as a summary score $\geq 30$ points on the CIPN20.

Results: With an overall response rate of $83 \%$ (2839 patients), prevalence of PN was 17\% overall, varying from 15 to $30 \%$ between diagnosis groups.

Conclusion: Symptoms of PN are experienced widely across cancer groups in the oncology setting and symptoms are correlated with patient-related factors as living alone, various comorbidities, polypharmacy, and cannabis use.

\section{Introduction}

During the last five decades, combination chemotherapy has been used to increase the survival of patients with cancer and many treatment regimens include neurotoxic components [1]. Chemotherapyinduced peripheral neuropathy (CIPN) is the most prevalent type of cancer-related peripheral neuropathy (PN) experienced by up to $37-84 \%$ of patients three months after ending treatment [2]. This is a high number, considering the detrimental and lasting effects PN can have on patients' quality of life (QoL) [3], and the lack of prevention and treatment options of CIPN [4].

CIPN exemplifies the etiological complexity of cancer-related peripheral neuropathies with numerous complex and inter-dependent disease mechanisms unfolding in multiple physiological systems [5]. More than 100 assessment strategies have been proposed [6], which is one of the reasons why rates of CIPN vary significantly depending on cancer patient group, treatment type and study design [6, 7].

Prevalence of peripheral neuropathy among the general middle-aged and elderly population has been estimated to be between 4-9\% [8]. No study has investigated an overall estimate of PN for the oncological population. Oncology PN estimates are specific for cancer patient subgroups only [2] and affected by limitations, including - but not limited to - misestimating/neglecting prevalence of motor- and autonomous neuropathy $[7,9]$, overrepresentation of homogenous datasets from uniform patient trajectories i.e. patients receiving neurotoxic chemotherapy in the adjuvant settings [2] and using data from before the era of immunotherapy and biological agents [2, 3], which can also induce PN [10].

These limitations coupled with the implications of PN pathophysiological heterogeneity [11] suggest that PN is even more widely distributed than expected from the available data. This study aimed to provide an 
overall picture of PN symptomatology in a general oncological population.

\section{Methods}

A cross-sectional, anonymous survey was conducted from April 22 to June 7, 2019. All patients aged 18 years or older and attending ambulatory services were eligible for inclusion. Patients could receive active treatment (chemotherapy, immunotherapy, targeted therapies, or radiotherapy) or attend as part of a follow-up visit. Patients without a cancer diagnosis were excluded. The study was conducted at the Departments of Clinical Oncology, Zealand University Hospital and the Department of Oncology, Odense University Hospital, Denmark.

\section{Questionnaire Formation}

The questionnaire was comprised of 91 items in total; 17 study-specific questions on sociodemographics, cancer disease, treatment, lifestyle and comorbidity, number of prescription medicines ( $>5$ prescription medicines was defined as polypharmacy), 7 study-specific questions on cannabis use, and the EORTCQLQ-C30 (C30), the EORTC-CIPN20 module (CIPN20), the GAD7 and the PHQ9 questionnaires [3, 12-14]. An internal multidisciplinary group revised and validated the survey questions and the questionnaire was reviewed by a board of patient and relative representatives.

A pilot study ( $\mathrm{N}=14)$ was conducted to evaluate the feasibility of the questionnaire as well as the validity, relevance and wording of the questions, using retrospective think-aloud interviews [15].

\section{Questionnaire conduction}

The survey was distributed within standard opening hours usually 8:30 AM to 3.00 PM, for a three-week period at each department. A serial number identified each survey. Surveys were tallied daily. Response rate was calculated by dividing the total surveys distributed with the total amount of completed surveys collected plus patient refusals. Patient refusal were not questioned, but when given freely, patients primarily refused because of time constraints and a few due to language barriers. Patients were assisted with completion of the questionnaires in cases of vision problems or paralysis/paresthesia.

\section{Exposure and outcomes}

A summary score was calculated based on items 1-18 of the CIPN20 consistent with recent studies and findings showing poor psychometric performance of the subscales $[9,16,17]$. A total score of 30 points or more on the CIPN20 score was used to divide patients into a high score and low score group [16, 17] using the high score as our definition of PN. We allowed for up to two missing items. Missing item values were imputed with the patient average score (preferentially rounded down), resulting in 34 patient score imputations.

The C30 scores, including five functioning scores, nine symptom scores, a global health score and the C30 Sum Score were calculated based on the EORTC 3rd Edition Manual [18]. 
Summary scores were calculated for the PHQ9 and GAD7. The PHQ9 and GAD7 summary scores were divided into a categorical variable of two levels using a cutoff point equal to or above 10 points $[19,20]$. At this cutoff, the likelihood ratio for the presence of a major depressive disorder is 7.1 with a sensitivity and specificity of $88 \%$ [19], and Spitzer et al reported in a study that most patients (89\%) with general anxiety disorder (GAD) had GAD-7 scores of 10 or greater, whereas most patients (82\%) without GAD had scores less than 10 [20]. We allowed for scoring of respondent total score for up to two missing items [21]. Average imputed scores were rounded down. This procedure was completed for 34 patient GAD7 scores, and 106 patient PHQ9 scores.

\section{Statistical analysis}

We used a two-sample, unpaired Wilcoxon test to test median difference in age and Pearson's chi squared test to test factors containing two categorical variables for proportional equality by CIPN20 high scores such as gender (male/female), active smoking (yes/no), active treatment (yes/no), cohabitation status (living with partner/living alone), presence of each comorbidity (yes/no), type of active treatment (yes/no), GAD7 (non-case/case) and PHQ9 (non-case/case). For age groups (<30, 30-49, 50-64, 65-80, $>80$ ), BMI categories (<18, 18-25, 25-30, > 30), education (mandatory school, upper secondary/vocational education, short higher education, medium-length higher education, long higher education), alcohol overconsumption (> 5 units at same occasion/daily, -/weekly, -/monthly, -/less than monthly, -/never), (never, less than monthly, monthly, weekly, daily) and number of prescription medicines $(0-3,4-5,>5)$ we used a binomial general linear model, presenting estimates as odds ratios (OR). Q-Q plots were graphed for each regression, establishing a normal distribution of residuals for univariate linear models. The definition of polypharmacy was set at $>5$ prescription medicines.

The C30 subscales differences were tested using logistic regression. Q-Q plots were graphed for each regression, establishing a normal distribution of residuals. Results from multivariate analysis were adjusted for age, gender, BMI and active treatment and cohabitation status. The calculated Variance Inflation Factor (VIF) of involved variables showed minimal collinearity.

Cohen's $d$ was calculated for unadjusted and adjusted mean differences defining effect sizes as negligible $(<0.25)$, small $(>0.25)$, medium $(>0.50)$ and large $(>0.75)$.

All statistical operations were done in R-Studio (ver.1.3.1093)

\section{Ethics}

The study was done in compliance with the tenets of the Declaration of Helsinki. The local regional Ethical Committee reviewed the study (record no. 18-000080). The invitation letter explained the purpose of the survey, the thematic nature of the questions, and emphasized the anonymity of the respondent. The project leads, sponsoring organization and sources of funding were named.

\section{Results}


Between April 22 to June 7, 2019, 3435 patients were invited to participate. Upon completion, 22 questionnaires were found ineligible for analyses as 8 were blank and 14 participants did not list a cancer diagnosis (Figure 1). A total of 2839 questionnaires were eligible for analysis resulting in a response rate of $83 \%$. Participant characteristics are summarized in Table 1. More women $(59 \%)$ than men $(41 \%)$ completed the questionnaires. Missing answers were minimal and between 2-4\% for most categories, albeit higher for alcohol consumption and cannabis use (30\% and $11 \%$, respectively).

\section{CIPN20: Prevalence and correlated parameters}

Of the 2839 participants, 2533 respondents had evaluable responses of the CIPN20, while 306 had not filled in or partially responded to the CIPN20. The cohort was divided into two groups based on the CIPN20 summary score. A total of 427 participants (17\%) scored 30 points or higher (high scorers) and 2107 (83\%) scored below (low scorers). Table 2 summarizes differences between high score and low score groups according to patient related and disease specific characteristics. Several characteristics were significantly correlated with a higher proportion of PN high scorers. They were older (median 69yr vs $67 y r, p=0.023)$, more often women ( $19 \%$ vs $14 \%, p=0.003)$, more lived alone $(21 \%$ vs $15 \%, p=0.0004)$, were smokers ( $21 \%$ vs $15 \%, p=0.019)$ ), experienced polypharmacy (OR $3.38, p<0.0001$ ), and used cannabis ( $29 \%$ vs $15 \%, p<0.0001)$. There were significantly less participants with a high score among males drinking more than 14 units alcohol per week (22\% vs $11 \% \mathrm{p}=0.0005)$ while this was not the case among women ( $15 \%$ vs $15 \% \mathrm{p}=0.877)$. The proportion of participants in the high score group did not differ on whether patients were actively receiving treatments ( $17 \%$ for both groups, $p=0.81)$. There were a higher proportion of high score patients among patients with diabetes ( $26 \%$ vs $16 \%, p<0.0001)$, cardiac heart disease (CHD) $(27 \%$ vs $16 \%, p<0.0001)$, arthritis ( $32 \%$ vs $15 \%, p<0.0001)$ or chronic obstructive pulmonary disease (COPD) ( $25 \%$ vs $16 \%, p=0.003)$ compared to patients without these comorbidities.

Patients with breast cancer constituted almost $35 \%$ of all participants in the high score group, but the prevalence of a high score among patients with breast cancer (19\%) was at the same level as for patients with upper gastro-intestinal, colorectal, and lung cancer (17-19\%) and less than the prevalence of a high score in patients with gynecological or pancreatic cancer (21-24\%). The highest prevalence was found among patients with cancers derived from bone and connective tissue (29\%) and CNS tumors (33\%) (Figure 2.).

\section{Quality of Life}

A high PN score was correlated with significantly worse mean scores on all C30 subscales when adjusting for age, gender, BMI, active treatment and cohabitation status (Table 3). The mean adjusted difference on the C30 SumScore was -18.66 ( $p<0.0001)$, representing a large effect size (Cohen's $d=$ 1.26) on overall QoL [22].

There were significantly more cases of anxiety ( $6 \%$ vs $20 \% \mathrm{p}=0.0001)$ and depression ( $8 \%$ vs $30 \%$ $\mathrm{p}=0.0001$ ) among participants with a PN high score measured with the GAD7 and PHQ9 respectively. 


\section{Discussion}

To our knowledge, this study is the largest study of PN in a general oncological population to date. The overall prevalence of PN was $17 \%$ and thus quite lower than CIPN estimates from prior studies $[2,3,23$, 24]. This is likely due to the heterogeneity of our cohort compared to the more homogenous cohorts in other studies. Our cohort contained patients in follow-up and remission as well as patients in the adjuvant, recurrent and palliative settings, receiving a plethora of other treatments than platinums, taxanes or vinca alkaloids. This study design resulted in a cross-sectional and broad view of PN to contrast the specific and focused view of previous studies. Viewed in this way, we found a general and somewhat equal distribution of PN among the most prevalent forms of cancer.

We found several patient-related factors associated with PN (score above 30 on the CIPN20). To our knowledge, this is the first study to associate PN with polypharmacy and cannabis use in an oncology population. Similar to us, prior studies have also found that age [25, 26], smoking [2] and alcohol consumption [27] are risk factors of CIPN while being married has been associated with less risk of CIPN [28]. However, not all studies show an association to these patient-related risk factors $[29,30]$ which may be due to cohort variations, definitions of covariates and limitations in research designs. For instance we found a higher proportion of women in the high score group, while other studies found CIPN equally distributed between genders [24,31], but most research on CIPN has actually been conducted on cohorts of one gender $[3,26,30]$. Due to the lack of information of specific types of chemotherapy and doses received, which may differ by gender, based on our data we are not able interpret this difference as reflecting differences in use of chemotherapy as has been argued by others [32]. Furthermore, many cross sectional studies of CIPN risk factors rarely report response rates and when they do, they have rates of around $60 \%$ [25] while in our population-based study we obtained a response rate of $83 \%$. Although this hopefully increases generalizability of our findings, we know from other health surveys that nonparticipants are more often men and patients with worse clinical outcomes [33]. Analysis of comorbidities found higher proportions of high scores among patients also sufferings from diabetes, coronary heart disease (CHD), chronic obstructive pulmonary disease (COPD) and arthritis. Arthritis and diabetes have inconsistently been identified as possible CIPN risk factors $[23,27,28,30,31,34]$ while the association with CHD and COPD seems a novel finding. These findings may reflect the ability of these diseases to cause PN in themselves through increased oxidative stress and inflammation [35-37]. Furthermore, since oxidative stress and inflammation are also CIPN pathophysiological mechanisms, attainment of these comorbidities is likely to influence the development of CIPN (and vice versa) $[5,10]$. This interdependency of networked pathophysiological mechanisms leading to PN should also be considered in discussion of the novel correlation to polypharmacy found here. Common drugs such as statins can cause PN [38] and antihypertensive drugs and antidiabetic drugs can influence pathophysiological mechanisms involved in development of CIPN [5, 39]. Novel methodologies such as system bioinformatics and machine learning are being employed to adequately capture and operationalize the large datasets of drug-drug/drug-gene interaction to yield new knowledge about drug interactions in $\mathrm{PN}$ pathophysiology $[40,41]$. 
In this study, having a high score on the CIPN20 was correlated with clinically meaningful worse scores on all subscales of the $\mathrm{C} 30$ even when adjusted for multiple confounders. Previous studies have found smaller differences on all subscales in patients with ovarian cancer (except diarrhea) [25] and patients with breast cancer [3] and CIPN.

The design of this study entails some limitations. Firstly, there is no validated diagnostic cutoff for PN on the CIPN20 score. Secondly, using items 1-18 on the CIPN20 implies using items with varied specificity. Prior studies found that items concerning the sensory qualities of CIPN are more reliable and better correlated with other PN measures than those concerning the autonomous qualities of neuropathy [16, 42]. However, it should be noted that this may stem from limitations and usage of said correlative measurement methods, which often measure only PN sensory qualities [43, 44]. These two design choices may influence the specificity of the PN estimates in our study. The heterogeneity of the sample and solely patient reported nature of the data, resulted in an absence of information on specific chemotherapy or other oncological treatments received. Neuropathy symptoms are not pathognomonic for cancer-related PN and may have arisen from other toxic substances (alcohol, vitamin deficiencies, diabetic), autoimmunity or genetic disorders [35]. We cannot, based on these data, distinguish neuropathy symptoms and severity of these to be based on chemotherapy, by other exposures, or by a combination hereof.

\section{Conclusion}

This study investigated symptoms of PN from the perspective of the clinical heterogeneity found in an out-patient oncology clinic. The findings suggest that PN may be a more universal problem in cancer care compared with findings from previous studies that focus on CIPN and suggest that there is more to be learned about cancer-related PN by studying the phenomenon outside patients in adjuvant treatments. Future studies should focus on PN manifestation stratified by associated comorbidities such as diabetes, $\mathrm{CHD}$ or arthritis, or PN symptom development through multiple lines of antineoplastic treatment. The study found novel important patient associated factors for PN such as having polypharmacy or using cannabis. Symptoms of PN were correlated with a large reduction in quality of life.

\section{Declarations}

Funding: The authors did not receive financial support from any organization for the submitted work.

Conflicts of interest: The authors have no relevant financial or non-financial interests to disclose.

Availability of data and material: Data can be shared for transparency purposes if requested.

Code availability: All statistical operations were done in R-Studio (ver.1.3.1093).

Authors' contributions: All authors contributed to the study conception and design. Material preparation, data collection and analysis were performed by Sebastian Werngreen Nielsen. The first draft of the 
manuscript was written by Sebastian Werngreen Nielsen and all authors commented on previous versions of the manuscript. All authors read and approved the final manuscript.

Ethics approval: This is an observational study. The regional ethics committee of Region Zealand has confirmed that no ethical approval is required. Record no. 18-000080.

Consent to participate: Verbal informed consent was obtained prior to participation.

\section{Consent for publication: N/A}

\section{References}

1. Staff NP, Grisold A, Grisold W, Windebank AJ (2017) Chemotherapy-induced peripheral neuropathy: A current review. Ann Neurol 81:772-781. https://doi.org/10.1002/ana.24951

2. Seretny M, Currie GL, Sena ES, et al (2014) Incidence, prevalence, and predictors of chemotherapyinduced peripheral neuropathy: A systematic review and meta-analysis. Pain 155:2461-2470. https://doi.org/10.1016/j.pain.2014.09.020

3. Eckhoff L, Knoop A, Jensen MB, Ewertz M (2015) Persistence of docetaxel-induced neuropathy and impact on quality of life among breast cancer survivors. Eur J Cancer 51:292-300. https://doi.org/10.1016/j.ejca.2014.11.024

4. Loprinzi CL, Lacchetti C, Bleeker J, et al (2020) Prevention and management of chemotherapyinduced peripheral neuropathy in survivors of adult cancers: ASCO guideline update. J Clin Oncol 38:3325-3348. https://doi.org/10.1200/JC0.20.01399

5. Starobova H, Vetter I (2017) Pathophysiology of Chemotherapy-Induced Peripheral Neuropathy. Front Mol Neurosci 10:174. https://doi.org/10.3389/fnmol.2017.00174

6. McCrary JM, Goldstein D, Boyle F, et al (2017) Optimal clinical assessment strategies for chemotherapy-induced peripheral neuropathy (CIPN): a systematic review and Delphi survey. Support Care Cancer 25:3485-3493. https://doi.org/10.1007/s00520-017-3772-y

7. Molassiotis A, Cheng HL, Lopez V, et al (2019) Are we mis-estimating chemotherapy-induced peripheral neuropathy? Analysis of assessment methodologies from a prospective, multinational, longitudinal cohort study of patients receiving neurotoxic chemotherapy. BMC Cancer 19:1-19. https://doi.org/10.1186/s12885-019-5302-4

8. Hanewinckel R, Drenthen J, Van Oijen M, et al (2016) Prevalence of polyneuropathy in the general middle-aged and elderly population. Neurology 87:1892-1898. https://doi.org/10.1212/WNL.0000000000003293

9. Wang M, Cheng HL, Lopez V, et al (2019) Redefining chemotherapy-induced peripheral neuropathy through symptom cluster analysis and patient-reported outcome data over time. BMC Cancer 19:110. https://doi.org/10.1186/s12885-019-6352-3

10. Stone JB, DeAngelis LM (2016) Cancer-treatment-induced neurotoxicity-focus on newer treatments. Nat Rev Clin Oncol 13:92-105. https://doi.org/10.1038/nrclinonc.2015.152 
11. Argyriou AA, Bruna J, Park SB, Cavaletti G (2020) Emerging pharmacological strategies for the management of chemotherapy-induced peripheral neurotoxicity (CIPN), based on novel CIPN mechanisms. Expert Rev Neurother 20:1005-1016.

https://doi.org/10.1080/14737175.2020.1796639

12. Groenvold M, Klee MC, Sprangers MAG, Aaronson NK (1997) Validation of the EORTC QLQ-C30 quality of life questionnaire through combined qualitative and quantitative assessment of patientobserver agreement. J Clin Epidemiol 50:441-450. https://doi.org/10.1016/S0895-4356(96)00428-3

13. Esser $P$, Hartung TJ, Friedrich $M$, et al (2018) The Generalized Anxiety Disorder Screener (GAD-7) and the anxiety module of the Hospital and Depression Scale (HADS-A) as screening tools for generalized anxiety disorder among cancer patients. Psychooncology 27:1509-1516. https://doi.org/10.1002/pon.4681

14. Pedersen SS, Mathiasen K, Christensen KB, Makransky G (2016) Psychometric analysis of the Patient Health Questionnaire in Danish patients with an implantable cardioverter defibrillator (The DEFIB-WOMEN study). J Psychosom Res 90:105-112. https://doi.org/10.1016/j.jpsychores.2016.09.010

15. Boren MT, Ramey J (2000) Thinking aloud: Reconciling theory and practice. IEEE Trans Prof Commun. https://doi.org/10.1109/47.867942

16. Le-Rademacher J, Kanwar R, Seisler D, et al (2017) Patient-reported (EORTC QLQ-CIPN20) versus physician-reported (CTCAE) quantification of oxaliplatin- and paclitaxel/carboplatin-induced peripheral neuropathy in NCCTG/Alliance clinical trials. Support Care Cancer 25:3537-3544. https://doi.org/10.1007/s00520-017-3780-y

17. Kieffer JM, Postma TJ, van de Poll-Franse L, et al (2017) Evaluation of the psychometric properties of the EORTC chemotherapy-induced peripheral neuropathy questionnaire (QLQ-CIPN20). Qual Life Res 26:2999-3010. https://doi.org/10.1007/s11136-017-1626-1

18. Giesinger JM, Kieffer JM, Fayers PM, et al (2016) Replication and validation of higher order models demonstrated that a summary score for the EORTC QLQ-C30 is robust. J Clin Epidemiol 69:79-88. https://doi.org/10.1016/j.jclinepi.2015.08.007

19. Manea L, Gilbody S, McMillan D (2012) Optimal cut-off score for diagnosing depression with the Patient Health Questionnaire (PHQ-9): a meta-analysis. Can Med Assoc J 184:E191-E196. https://doi.org/10.1503/cmaj.110829

20. Spitzer RL, Kroenke K, Williams JBW, Löwe B (2006) A Brief Measure for Assessing Generalized Anxiety Disorder. Arch Intern Med 166:1092. https://doi.org/10.1001/archinte.166.10.1092

21. Arrieta J, Aguerrebere M, Raviola G, et al (2017) Validity and Utility of the Patient Health Questionnaire (PHQ)-2 and PHQ-9 for Screening and Diagnosis of Depression in Rural Chiapas, Mexico: A Cross-Sectional Study. J Clin Psychol 73:1076-1090. https://doi.org/10.1002/jclp.22390

22. Sawilowsky SS (2009) New Effect Size Rules of Thumb. J Mod Appl Stat Methods 8:597-599. https://doi.org/10.22237/jmasm/1257035100 
23. Greenwald MK, Ruterbusch JJ, Beebe-Dimmer JL, et al (2019) Risk of incident claims for chemotherapy-induced peripheral neuropathy among women with breast cancer in a Medicare population. Cancer 125:269-277. https://doi.org/10.1002/cncr.31798

24. Shah A, Hoffman EM, Mauermann ML, et al (2018) Incidence and disease burden of chemotherapyinduced peripheral neuropathy in a populationbased cohort. J Neurol Neurosurg Psychiatry 89:636-641. https://doi.org/10.1136/jnnp-2017-317215

25. Ezendam NPM, Pijlman B, Bhugwandass C, et al (2018) Chemotherapy-induced peripheral neuropathy and its impact on health-related quality of life among ovarian cancer survivors: results from the population-based PROFILES registry. Gynecol Oncol 135:510-7. https://doi.org/10.1124/jpet.117.245704

26. Bulls HW, Hoogland Al, Kennedy B, et al (2019) A longitudinal examination of associations between age and chemotherapy-induced peripheral neuropathy in patients with gynecologic cancer. Gynecol Oncol 152:310-315. https://doi.org/10.1016/j.ygyno.2018.12.002

27. Molassiotis A, Cheng HL, Leung KT, et al (2019) Risk factors for chemotherapy-induced peripheral neuropathy in patients receiving taxane- and platinum-based chemotherapy. Brain Behav 9:1-10. https://doi.org/10.1002/brb3.1312

28. Nyrop KA, Deal AM, Reeder-Hayes KE, et al (2019) Patient-reported and clinician-reported chemotherapy-induced peripheral neuropathy in patients with early breast cancer: Current clinical practice. Cancer 125:2945-2954. https://doi.org/10.1002/cncr.32175

29. Hershman DL, Till C, Wright JD, et al (2016) Comorbidities and Risk of Chemotherapy-Induced Peripheral Neuropathy Among Participants 65 Years or Older in Southwest Oncology Group Clinical Trials. J Clin Oncol 34:3014-3022. https://doi.org/10.1200/JC0.2015.66.2346

30. Simon NB, Danso MA, Alberico TA, et al (2017) The prevalence and pattern of chemotherapy-induced peripheral neuropathy among women with breast cancer receiving care in a large community oncology practice. Qual Life Res 26:2763-2772. https://doi.org/10.1007/s11136-017-1635-0

31. Bonhof CS, Trompetter HR, Vreugdenhil G, et al (2020) Painful and non-painful chemotherapyinduced peripheral neuropathy and quality of life in colorectal cancer survivors: results from the population-based PROFILES registry. Support Care Cancer 28:5933-5941. https://doi.org/10.1007/s00520-020-05438-5

32. Smith EML, Zanville N, Kanzawa-Lee G, et al (2019) Rasch model-based testing of the European Organisation for Research and Treatment of Cancer (EORTC) Quality of Life QuestionnaireChemotherapy-Induced Peripheral Neuropathy (QLQ-CIPN20) using Alliance for Clinical Trials in Oncology (Alliance) A151408 stu. Support Care Cancer 27:2599-2608. https://doi.org/10.1007/s00520-018-4553-y

33. Knudsen AK, Hotopf M, Skogen JC, et al (2010) The health status of nonparticipants in a populationbased health study. Am J Epidemiol 172:1306-1314. https://doi.org/10.1093/aje/kwq257

34. Jesse M (2019) The relationship of chemotherapy-induced peripheral neuropathy and obesity: A systematic review. Rehabil Oncol 37:167-175. https://doi.org/10.1097/01.RE0.0000000000000183 
35. Smith DI, Tran HT, Poku J (2018) Hemodynamic Considerations in the Pathophysiology of Peripheral Neuropathy. In: Blood Pressure - From Bench to Bed. InTech, p (online)

36. Kahnert K, Föhrenbach M, Lucke T, et al (2020) The impact of COPD on polyneuropathy: Results from the German COPD cohort COSYCONET. Respir Res 21:1-10. https://doi.org/10.1186/s12931-020$1293-6$

37. Mols F, van de Poll-Franse L V., Vreugdenhil G, et al (2016) Reference data of the European Organisation for Research and Treatment of Cancer (EORTC) QLQ-CIPN20 Questionnaire in the general Dutch population. Eur J Cancer 69:28-38. https://doi.org/10.1016/j.ejca.2016.09.020

38. Jones MR, Urits I, Wolf J, et al (2019) Drug-Induced Peripheral Neuropathy: A Narrative Review. Curr Clin Pharmacol. https://doi.org/10.2174/1574884714666190121154813

39. Areti A, Komirishetty P, Kumar A (2017) Carvedilol prevents functional deficits in peripheral nerve mitochondria of rats with oxaliplatin-evoked painful peripheral neuropathy. Toxicol Appl Pharmacol 322:97-103. https://doi.org/10.1016/j.taap.2017.03.009

40. Bloomingdale P, Mager DE (2019) Machine Learning Models for the Prediction of ChemotherapyInduced Peripheral Neuropathy. Pharm Res. https://doi.org/10.1007/s11095-018-2562-7

41. de Anda-Jáuregui G, McGregor BA, Guo K, Hur J (2019) A Network Pharmacology Approach for the Identification of Common Mechanisms of Drug-Induced Peripheral Neuropathy. CPT Pharmacometrics Syst Pharmacol 8:211-219. https://doi.org/10.1002/psp4.12383

42. Alberti P, Rossi E, Cornblath DR, et al (2014) Physician-assessed and patient-reported outcome measures in chemotherapy-induced sensory peripheral neurotoxicity: Two sides of the same coin. Ann Oncol 25:257-264. https://doi.org/10.1093/annonc/mdt409

43. Argyriou AA, Park SB, Islam B, et al (2019) Neurophysiological, nerve imaging and other techniques to assess chemotherapy-induced peripheral neurotoxicity in the clinical and research settings. $J$ Neurol Neurosurg Psychiatry 90:1361 LP - 1369. https://doi.org/10.1136/jnnp-2019-320969

44. Coumbe BGT, Groarke JD (2018) Cardiovascular Autonomic Dysfunction in Patients with Cancer. Curr Cardiol Rep 20:10-17. https://doi.org/10.1007/s11886-018-1010-y

\section{Tables}


Table 1: Sociodemography, lifestyle, comorbidity and cancer characteristics in in a cross-sectional sample of patients in outpatient oncology care

\begin{tabular}{|c|c|c|c|c|}
\hline & $\mathrm{N}$ & $\%$ & Range & Missing \\
\hline Age (years) & 2775 & & $18-99$ & $2 \%$ \\
\hline$<30$ & 33 & 1 & & \\
\hline $30-49$ & 298 & 11 & & \\
\hline $50-64$ & 837 & 30 & & \\
\hline $65-80$ & 1372 & 49 & & \\
\hline$>80$ & 235 & 8 & & \\
\hline Gender & 2776 & & & $2 \%$ \\
\hline Female & 1646 & 59 & & \\
\hline Male & 1130 & 41 & & \\
\hline Education & 2736 & & & $4 \%$ \\
\hline Mandatory school & 519 & 19 & & \\
\hline Upper secondary school/vocational education & 1089 & 40 & & \\
\hline Short higher education & 343 & 13 & & \\
\hline Medium-length higher education & 585 & 21 & & \\
\hline Long higher education & 200 & 7 & & \\
\hline Cohabitation status & 2761 & & & $3 \%$ \\
\hline Living with partner & 1981 & 72 & & \\
\hline Living alone & 780 & 28 & & \\
\hline BMI & 2739 & & $14-76$ & $4 \%$ \\
\hline
\end{tabular}




$\begin{array}{lrc}<18 & 78 & 3 \\ 18-24 & 1163 & 42 \\ 25-30 & 936 & 34 \\ >30 & 562 & 21\end{array}$

\section{Smoking status}

Current smoker

Never smoker

Former smoker

Alcohol intake

Yes

No

Weekly units of alcohol by gender

Men

$1-14$

$>14$

Null or unknown

Women

$<7$

$>7$

Null or unknown

\begin{tabular}{rr}
478 & 17 \\
\hline 1518 & 55 \\
\hline 785 & 28
\end{tabular}

2726

$4 \%$

199273

$734 \quad 27$

869

$0-60$

$612 \quad 70$

$145 \quad 17$

$112 \quad 13$

1083

$0-42$

$715 \quad 66$

$182 \quad 17$

$186 \quad 17$


Thyroid disorder

Chronic obstructive lung disease

Osteoporosis

Cardiac heart disease

Diabetes

Arthritis

Asthma

Anxiety and depression

Connective tissue disorder

Don't know

No. prescription medications

0 - 3

4 - 5

$>5$

Type of cancer (multiple choice)

Head and neck

Upper GI (incl. liver)

Gynecological

Colorectal

Pancreatic

Bladder and kidney

Lung

Prostate
$156 \quad 5.4$

$188 \quad 6.6$

$157 \quad 5.5$

$305 \quad 11.0$

$265 \quad 9.3$

$283 \quad 10.0$

$171 \quad 6.0$

$151 \quad 5.3$

$\begin{array}{ll}52 & 1.8\end{array}$

$54 \quad 1.9$

168962

$499 \quad 18$

$556 \quad 20$

2839

\begin{tabular}{rr}
\hline 195 & 6.0 \\
\hline 184 & 5.7 \\
\hline 200 & 6.1 \\
\hline 376 & 11.6 \\
\hline 110 & 3.4 \\
\hline 134 & 4.1 \\
\hline 527 & 16.2 \\
\hline 253 & 7.8 \\
\hline
\end{tabular}

Page 14/23 


\begin{tabular}{|c|c|c|c|}
\hline Testicular & 50 & 1.5 & \\
\hline Blood and lymfoid & 63 & 1.9 & \\
\hline Breast & 842 & 25.9 & \\
\hline Bone and other connective tissue & 55 & 1.7 & \\
\hline CNS & 68 & 2.1 & \\
\hline Melanoma & 196 & 6.0 & \\
\hline In active treatment & 2754 & & $3 \%$ \\
\hline Yes & 1847 & 67 & \\
\hline In control or between treatments & 535 & 19 & \\
\hline No & 374 & 14 & \\
\hline Type of active treatment (multiple choice) & 1847 & & $\mathrm{n} / \mathrm{a}$ \\
\hline Chemotherapy & 989 & 54 & \\
\hline Radiotherapy & 322 & 17 & \\
\hline Anti-hormonal therapy & 353 & 19 & \\
\hline Immunotherapy & 200 & 11 & \\
\hline Unknown & 114 & 6 & \\
\hline Cannabis use at any time during treatment & 2539 & & $11 \%$ \\
\hline Yes & 326 & 13 & \\
\hline No & 2213 & 87 & \\
\hline
\end{tabular}


Table 2: Differences in demographics in CIPN20 low scorers compared to high scorers ( $\geq 30$ points) in a cross-sectional sample of patients in outpatient oncology care

\begin{tabular}{|c|c|c|c|c|}
\hline & Low-score & High-score & Specified & $\mathrm{p}$-value \\
\hline & $n=2106$ & $N=427$ & & \\
\hline Age (median) & 67 & 69 & & 0.023 \\
\hline Age groups & $\mathrm{n}$ & $\mathrm{n}$ & OR \& Cl-95 & $\mathrm{p}$ \\
\hline$<30$ & 31 & 1 & $\begin{array}{l}0.15 \\
{[0.008 ; 0.70]}\end{array}$ & 0.062 \\
\hline $30-49$ & 234 & 42 & $0.83[0.57 ; 1.18]$ & 0.319 \\
\hline $50-64$ & 645 & 124 & $0.89[0.69 ; 1.13]$ & 0.355 \\
\hline $65-80$ & 1007 & 217 & ref & ref \\
\hline$>80$ & 147 & 37 & $1.16[0.78 ; 1.70]$ & 0.434 \\
\hline Education & $\mathrm{n}$ & $\mathrm{n}$ & OR \& Cl-95 & $\mathrm{p}$ \\
\hline Mandatory school & 348 & 90 & ref & ref \\
\hline $\begin{array}{l}\text { Upper secondary school/vocational } \\
\text { education }\end{array}$ & 823 & 158 & $0.74[0.56 ; 0.99]$ & 0.042 \\
\hline Short higher education & 240 & 67 & $1.08[0.74 ; 1.54]$ & 0.674 \\
\hline Medium-length higher education & 476 & 73 & $0.59[0.42 ; 0.83]$ & 0.002 \\
\hline Long higher education & 161 & 25 & $0.60[0.36 ; 0.96]$ & 0.037 \\
\hline Gender & $\mathrm{n}$ & $\mathrm{n}$ & $\%$ high score & $\mathrm{p}$ \\
\hline Women & 1193 & 274 & 19 & 0.003 \\
\hline Men & 870 & 146 & 14 & \\
\hline Cohabitee status & $\mathrm{n}$ & $\mathrm{n}$ & $\%$ high score & $\mathrm{p}$ \\
\hline
\end{tabular}




\begin{tabular}{|c|c|c|c|c|}
\hline Yes & 1527 & 532 & 15 & 0.0004 \\
\hline No & 275 & 144 & 21 & \\
\hline \multirow[t]{2}{*}{ BMI (mean) } & & & OR \& Cl-95 & $\mathrm{p}$ \\
\hline & 26.17 & 26.65 & {$[-1.1 ; 0.15]$} & 0.136 \\
\hline BMI class & $\mathrm{n}$ & $\mathrm{n}$ & OR \& Cl-95 & $\mathrm{p}$ \\
\hline$<18$ & 52 & 16 & $1.59[0.86 ; 2.80]$ & 0.117 \\
\hline $18-25$ & 871 & 168 & ref & ref \\
\hline $25-30$ & 708 & 130 & $0.95[0.74 ; 1.22]$ & 0.699 \\
\hline$>30$ & 409 & 102 & $1.29[0.98 ; 1.69]$ & 0.065 \\
\hline Smoking status & $\mathrm{n}$ & $\mathrm{n}$ & $\%$ high score & $\mathrm{p}$ \\
\hline Yes & 339 & 88 & 21 & 0.019 \\
\hline No & 1739 & 327 & 16 & \\
\hline Alcohol status & $\mathrm{n}$ & $\mathrm{n}$ & $\%$ high score & $\mathrm{p}$ \\
\hline Yes & 1547 & 257 & 14 & $<0.0001$ \\
\hline No & 502 & 152 & 23 & \\
\hline Alcohol use (units/week) & $\mathrm{n}$ & $\mathrm{n}$ & $\%$ high score & $\mathrm{p}$ \\
\hline \multicolumn{5}{|l|}{ Men } \\
\hline$\leq 14$ & 495 & 62 & 11 & 0.0005 \\
\hline$>14$ & 104 & 31 & 22 & \\
\hline
\end{tabular}


Women

$\begin{array}{rrrrr}\leq 7 & 552 & 101 & 15 & 0.877 \\ >7 & 146 & 25 & 15\end{array}$

Alcohol $>5$ units at same occasion

n

n

OR \& Cl-95

p

Never

680

134

ref

ref

Less than monthly

699

113

$0.82[0.62 ; 1.08]$

0.153

Monthly

240

38

$0.80[0.54 ; 1.17]$

0.27

Weekly

94

13

$0.70[0.36 ; 1.28]$

0.254

Daily

15

8

$2.70[1.07 ; 6.36] \quad 0.026$

\section{Cannabis use}

n

n

$\%$ high score

$\mathrm{p}$

Yes

209

84

29

$<0.0001$

No

1735

310

15

No. of different prescription medications

$\mathrm{n}$

n

OR \& Cl-95

$\mathrm{p}$

0-3

1373

178

ref

ref

4-5

359

95

$2.04[1.55 ; 2.68] \quad<0.0001$

$>5$

330

145

$3.38[2.64 ; 4.35]$

$<0.0001$

Active treatment

$\mathrm{n}$

$\mathrm{n}$

$\%$ high score

p

Yes

1407

282

17

0.81

No

666

138

17 
Type of active treatment

Proportion with high score

Cl-95

$\mathrm{p}$

Treatment:

No Yes

Chemotherapy

$15.7 \%$

$17.6 \%$

$[-0 ; 06 ; 0.02]$

0.344

Radiotherapy

$16.5 \%$

$17.4 \%$

$[-0.06 ; 0.04]$

0.765

Anti-hormonal therapy

$17.0 \%$

$16.1 \%$

$[-0.03 ; 0.06]$

0.572

Immunotherapy

$17.4 \%$

$9.6 \%$

[0.03;0.12]

0.005

\section{Comorbidities}

Proportion with high score

Cl-95

p

Comorbidity present:

Thyroid disorder

Chronic obstructive lung disease

Osteoporosis

Cardiac heart disease

Diabetes

Arthritis

Asthma

Anxiety and depression

Connective tissue disorder
No

$16.4 \%$

$16.2 \%$

$16.5 \%$

$15.6 \%$

$15.8 \%$

$15.1 \%$

$16.6 \%$

$16.6 \%$

$16.6 \%$
$23.7 \%$

$[-0 ; 15 ; 0.003]$

$[-0.16 ;-0.02]$

$[-0.13 ;-0.02]$

[-0.17;-0.06]

[-0;17;-0.05]

$[-0.23 ;-0.11]$

$[-0.11 ;-0.03]$

0.251

$20.5 \%$

$21.3 \%$

$[-0.12 ;-0.03]$

$30.6 \%$ $[-0.28 ; 0.00002]$
0.185

0.034

0.003

0.091

$<0.001$

$<0.001$

$<0.001$

0.251

0.016


Table 3. Health related quality of life for CIPN low scorers vs high scorers among a cross sectional sample of patients in outpatient oncology care

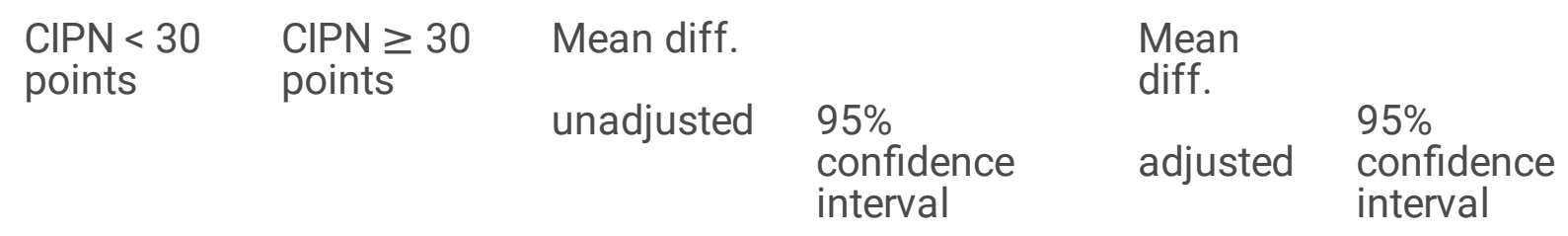

EORTC QoL $\quad \mathrm{n}=2106 \quad \mathrm{n}=427$

C30

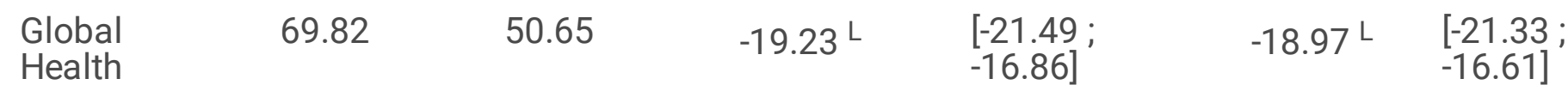

\begin{tabular}{|c|c|c|c|c|c|c|}
\hline $\begin{array}{l}\text { Physical } \\
\text { function }\end{array}$ & 80.38 & 55.39 & $-23.99^{L}$ & $\begin{array}{l}{[-26.19 ;} \\
-21.79]\end{array}$ & $-23.41^{L}$ & $\begin{array}{l}{[-25.62 ;} \\
-21.19]\end{array}$ \\
\hline $\begin{array}{l}\text { Role } \\
\text { function }\end{array}$ & 73.69 & 45.37 & $-28.31^{L}$ & $\begin{array}{l}{[-31.53} \\
-25.10]\end{array}$ & $-28.36^{L}$ & $\begin{array}{l}{[-31.65 ;} \\
-25.07]\end{array}$ \\
\hline $\begin{array}{l}\text { Emotionel } \\
\text { function }\end{array}$ & 83.73 & 68.90 & $-14.83^{M}$ & $\begin{array}{l}\text { [-16.93; } \\
-12.72]\end{array}$ & $-15.04^{M}$ & $\begin{array}{l}{[-17.16 ;} \\
-12.91]\end{array}$ \\
\hline $\begin{array}{l}\text { Cognitive } \\
\text { function }\end{array}$ & 85.50 & 63.29 & $-22.21^{L}$ & $\begin{array}{l}{[-24.45} \\
-19.97]\end{array}$ & $-21.98^{L}$ & $\begin{array}{l}{[-24.24 ;} \\
-19.72]\end{array}$ \\
\hline $\begin{array}{l}\text { Social } \\
\text { function }\end{array}$ & 85.44 & 63.88 & $-21.56^{L}$ & $\begin{array}{l}{[-23.98} \\
-19.15]\end{array}$ & $-21.83^{L}$ & $\begin{array}{l}\text { [-24.29; } \\
-19.37]\end{array}$ \\
\hline Fatigue & 33.84 & 61.26 & $27.44^{L}$ & {$[24.77 ; 30.11]$} & $26.93^{L}$ & $\begin{array}{l}{[24.21 ;} \\
29.65]\end{array}$ \\
\hline $\begin{array}{l}\text { Nausea \& } \\
\text { vomiting }\end{array}$ & 7.22 & 15.21 & $7.98^{s}$ & {$[6.27 ; 9.70]$} & $8.36^{M}$ & $\begin{array}{l}\text { [6.17 } \\
10.11]\end{array}$ \\
\hline Pain & 19.76 & 47.77 & $28.01^{L}$ & {$[25.23 ; 30.79]$} & $27.40^{L}$ & $\begin{array}{l}{[24.54 ;} \\
30.27]\end{array}$ \\
\hline Dyspnoea & 17.73 & 37.51 & $19.78^{M}$ & {$[16.88 ; 22.67]$} & $19.21^{L}$ & $\begin{array}{l}{[16.28 ;} \\
22.15]\end{array}$ \\
\hline Insomnia & 22.94 & 40.30 & $17.36^{\mathrm{M}}$ & {$[14.22 ; 20.51]$} & $17.06^{M}$ & $\begin{array}{l}{[13.88 ;} \\
20.24]\end{array}$ \\
\hline Appetite loss & 16.40 & 30.48 & $14.07^{\mathrm{M}}$ & {$[11.02 ; 17.12]$} & $14.28^{M}$ & $\begin{array}{l}{[11.19 ;} \\
17.37]\end{array}$ \\
\hline
\end{tabular}




\begin{tabular}{|c|c|c|c|c|c|c|}
\hline Constipation & 11.32 & 22.96 & $11.64^{S}$ & {$[9.14 ; 14.14]$} & $11.42^{\mathrm{S}}$ & $\begin{array}{l}\text { [8.86; } \\
13.99]\end{array}$ \\
\hline Diarrhoea & 12.86 & 22.75 & $9.90^{\mathrm{S}}$ & {$[7.36 ; 12.43]$} & $10.32^{\mathrm{s}}$ & $\begin{array}{l}{[7.76 ;} \\
12.90]\end{array}$ \\
\hline $\begin{array}{l}\text { Financial } \\
\text { difficulty }\end{array}$ & 6.78 & 17.99 & $11.21^{M}$ & {$[9.03 ; 13.39]$} & $11.96^{M}$ & $\begin{array}{l}{[9.76 ;} \\
14.16]\end{array}$ \\
\hline SumScore & 82.03 & 64.53 & $-18.78^{L}$ & $\begin{array}{l}{[-20.40} \\
-17.16]\end{array}$ & $-18.66^{L}$ & $\begin{array}{l}{[-20.31 ;} \\
-17.02]\end{array}$ \\
\hline \multicolumn{7}{|c|}{ Table 3a. Likely cases of anxiety and depression. based on cutoff scores from the GAD7 and PHQS } \\
\hline GAD7 & $N=2055$ & $N=409$ & $\%$ diff & $\begin{array}{l}95 \% \\
\text { confidence } \\
\text { interval }\end{array}$ & $\mathrm{p}$ & \\
\hline $\begin{array}{l}\text { Cases } \\
\text { (cutoff } \geq \\
10)\end{array}$ & 122 & 82 & 0.14 & $0.09 ; 0.18$ & 0.0001 & \\
\hline PHQ9 & $N=2004$ & $N=393$ & $\%$ diff & $\begin{array}{l}95 \% \\
\text { confidence } \\
\text { interval }\end{array}$ & $\mathrm{p}$ & \\
\hline $\begin{array}{l}\text { Cases } \\
\text { (cutoff } \geq \\
10)\end{array}$ & 158 & 117 & 0.22 & $0.17 ; 0.27$ & 0.0001 & \\
\hline
\end{tabular}

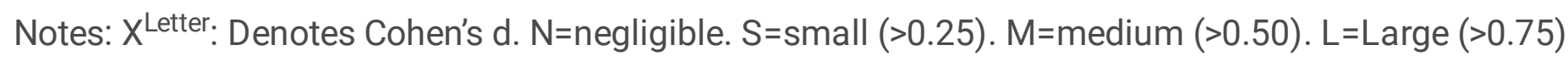
Abbrevations: Diff. $=$ Difference. CIPN = Chemotherapy-induced peripheral neuropathy. EORTC = European Organisation for Research and Treatment of Cancer. QoL = Quality of Life. GAD7 = General Anxiety Disorder (7 Items). PHQ9 = Patient Health Questionnaire (9 items).

\section{Figures}


3534 Invited

\section{Declined}

\section{Accepted}

\section{Blank}

14 No diagnoses

\section{Included in Analysis}

Figure 1

Flow chart of participants in cross-sectional study of cancer-related peripheral neuropathy among Danish oncological patients from April 22 to June 7, 2019 


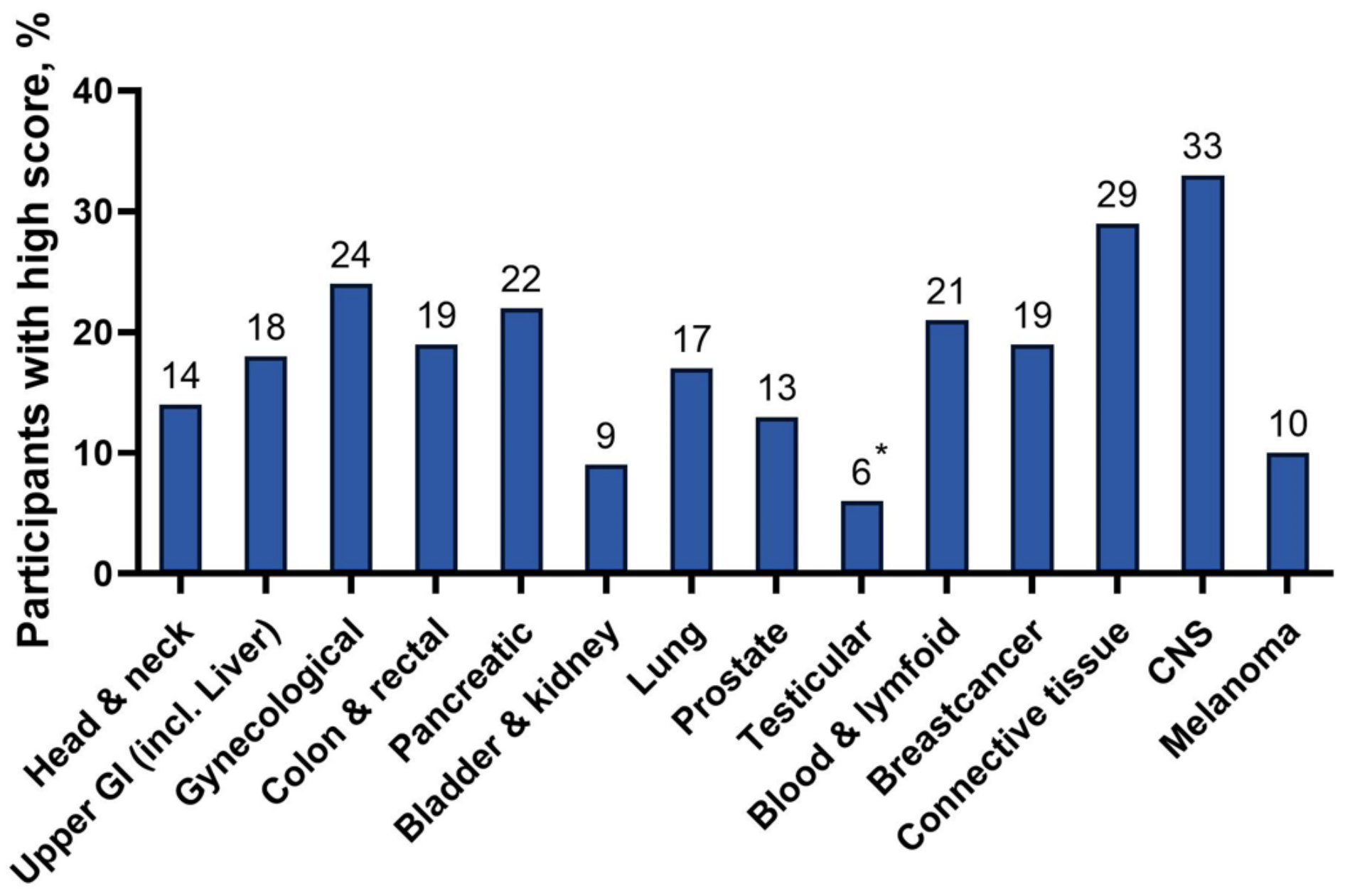

Cancer diagnoses

Figure 2

Prevalence of PN high scorers ( $\geq 30$ point summary score on the EORTC CIPN-20) relative to diagnosis group in a cross sectional study of 2533 Danish oncological patients. $*$ = Patients with testicular cancer predominantly not in active treatment 